\title{
The effects of intravenous dexmedetomidine on spinal anesthesia: comparision of different dose of dexmedetomidine
}

\author{
Mi Hyeon Lee, Jae Houn Ko, Eun Mi Kim, Mi Hwa Cheung, Young Ryong Choi, and Eun Mi Choi \\ Department of Anesthesiology and Pain Medicine, Kangnam Sacred Heart Hospital, Hallym University College of Medicine, Seoul, \\ Korea
}

Background: In this prospective, randomized, double-blind, placebo-controlled trial, we tried to find out appropriate amounts of single-dose dexmedetomidine to prolong the duration of spinal anesthesia in a clinical setting.

Methods: Sixty patients who were scheduled for unilateral lower limb surgery under spinal anesthesia were randomized into three groups receiving normal saline (control group, $\mathrm{n}=20$ ) or 0.5 or $1.0 \mathrm{ug} / \mathrm{kg}$ dexmedetomidine (D-0.5 group, $\mathrm{n}=20 ; \mathrm{D}-1, \mathrm{n}=20$ ) intravenously prior to spinal anesthesia with $12 \mathrm{mg}$ of bupivacaine. The two-dermatome pinprick sensory regression time, duration of the motor block, Ramsay sedation score (RSS), and side effects of dexmedetomidine were assessed.

Results: The two-dermatome pinprick sensory regression time (57.6 \pm 23.2 vs $86.5 \pm 24.3$ vs $92.5 \pm 30.7, \mathrm{P}=0.0002)$ and duration of the motor block ( $98.8 \pm 34.1$ vs $132.9 \pm 43.4$ vs $130.4 \pm 50.4, \mathrm{P}=0.0261)$ were significantly increased in the D- 0.5 and D-1 groups than in the control group. The RSS were significantly higher in the D- 0.5 and D-1 groups than in the control group. However, there were no patients with oxygen desaturation in dexmedetomidine groups. The incidences of hypotension and bradycardia showed no differences among the three groups.

Conclusions: Both 0.5 and $1.0 \mathrm{ug} / \mathrm{kg}$ of dexmedetomidine administered as isolated boluses in the absence of maintenance infusions prolonged the duration of spinal anesthesia. (Korean J Anesthesiol 2014; 67: 252-257)

Key Words: Bupivacaine, Dexmedetomidine, Spinal anesthesia.

Received: April 29, 2014. Revised: 1st, June 13, 2014; 2nd, June 30, 2014; 3rd, July 3, 2014; 4th, July 3, 2014; 5th, July 7, 2014. Accepted: July 7, 2014. Corresponding author: Eun Mi Choi, M.D., Ph.D., Department of Anesthesiology and Pain Medicine, Kangnam Sacred Heart Hospital, Hallym University College of Medicine, 1, Singil-ro, Yeongdeungpo-gu, Seoul 150-950, Korea. Tel: 82-2-2227-4964, Fax: 82-2-2227-7897, E-mail: emchoi96@hallym.or.kr

(c) This is an open-access article distributed under the terms of the Creative Commons Attribution Non-Commercial License (http:// creativecommons.org/licenses/by-nc/3.0/), which permits unrestricted non-commercial use, distribution, and reproduction in any medium, provided the original work is properly cited. 


\section{Introduction}

Dexmedetomidine is a highly selective $\alpha 2$-adrenergic agonist that provides analgesic and anesthetic-sparing effects $[1,2]$. In addition, because it affects the locus ceruleus area, which is associated with the modulation of sleep and respiration, it has a sedative effect with minimal respiratory depression $[3,4]$. In previous studies, intravenous administration of dexmedetomidine before or after spinal anesthesia prolonged the duration of sensory and motor block [5-9]. Commonly used intravenous methods of dexmedetomidine include a single-dose intravenous administration [5-7] before or after spinal anesthesia and a loading dose followed by continuous infusion [8,9]. However, a loading dose followed by continuous infusion has been reported to increase the incidence of hypotension and bradycardia $[9,10]$. A number of clinical studies have reported the effects of single-dose intravenous dexmedetomidine on spinal anesthesia with various amounts, ranging from 0.25 to $1 \mu \mathrm{g} / \mathrm{kg}$ [5-10]. In general, these studies have compared a control group and an experimental group in which patients are administered only one fixed amount of dexmedetomidine [6,8-10]. A few studies have directly compared different amounts of dexmedetomidine.

Therefore, we evaluated whether different amounts $(0.5 \mu \mathrm{g} / \mathrm{kg}$ and $1.0 \mu \mathrm{g} / \mathrm{kg}$ ) of single-dose intravenous dexmedetomidine before spinal anesthesia would cause different durations of spinal anesthesia. We also evaluated sedation scores, and dexmedetomidine-related side effects. Through this double blind, randomized placebo-controlled clinical study, we tried to find out the appropriate amounts of single-dose dexmedetomidine for prolongation duration of spinal anesthesia in a clinical setting.

\section{Materials and Methods}

After receiving approval from the Institutional Review Board of our hospital, 60 adult patients who were scheduled for surgery under spinal anesthesia were enrolled in this study. Written informed consent was obtained in all cases. All subjects had an American Society of Anesthesiologists physical status classification of either I or II, and all were between the ages of 18 and 65 years. This study was conducted from July 2013 to January 2014. Patients were excluded from this study if they had contraindications to regional anesthesia, including coagulopathy, or local skin infection, uncontrolled hypertension, diabetes, cardiopulmonary disease, and/or a body mass index of less than 18.5 or greater than $30 \mathrm{~kg} / \mathrm{m}^{2}$. Nursing staff blind to the purposes of the study randomly allocated patients to one of three groups (the control, the D-0.5, and the D-1 group) using a computergenerated randomization table.

Because the supine position should be maintained and at least one leg should be left free to test motor function during surgery, patients who were scheduled for unilateral lower limb surgery under spinal anesthesia were preferred. One anesthesiologist took charge of preparing the study drug before the patients arrived in the operating room. The prepared solution was a mixture of normal saline $(20 \mu \mathrm{g} / \mathrm{ml}$ of dexmedetomidine, a total volume of $10 \mathrm{ml}$ within a $20 \mathrm{ml}$ syringe). We used dosages of $0.5 \mu \mathrm{g} / \mathrm{kg}$ and $1.0 \mu \mathrm{g} / \mathrm{kg}$ of dexmedetomidine (Precedex ${ }^{\circledR}$; Hospira, Rocky Mount, NC, USA, $200 \mu \mathrm{g} / 2 \mathrm{ml}$ ) for the D-0.5 and D-1 groups, respectively, and only normal saline for the control group. There were no labels on the syringes. After the preparation of the drug, another anesthesiologist blind to the patients' groups took charge of the induction and monitoring of anesthesia during the surgery.

None of the patients received premedication. Upon arrival in the operating room, standard monitoring devices including an electrocardiogram, a pulse oximeter, and a noninvasive blood pressure cuff were applied. Before undergoing spinal anesthesia, all patients were administered $500 \mathrm{ml}$ of lactated Ringer's solution for pre-loading, after which the study drug was administered over a $10 \mathrm{~min}$ period. The baseline mean arterial pressure (MAP), heart rate (HR), and pulse oxygen saturation $\left(\mathrm{SpO}_{2}\right)$ were recorded. Five minutes after end of study drug infusion, the patient was placed in the lateral decubitus position. Spinal anesthesia was performed at the midline of the L4-5 interspinous space. After the intradermal infiltration of $3 \mathrm{ml}$ of $2 \%$ lidocaine for local anesthesia, a 25-gauge Sprotte needle was used for a lumbar puncture. When a free flow of cerebrospinal fluid was confirmed, $12 \mathrm{mg}$ of $0.5 \%$ hyperbaric bupivacaine (Marcaine ${ }^{\circledR}$, Astra Zeneca, Sweden) was injected into the subarachnoid space for $20 \mathrm{sec}$. Following the spinal anesthesia, patients were repositioned to the supine position and received $5 \mathrm{~L} / \mathrm{min}$ of oxygen via a facial mask.

The sensory block level was assessed by testing the loss of pinprick sensation with a blunt 25-guage needle along the midclavicular line bilaterally. The motor block level was assessed according to the Modified Bromage Scale ( $0=$ no paralysis; 1 = unable to raise extended leg; 2 = unable to flex knee; $3=$ unable to flex ankle) [11]. The sensory block level and the modified Bromage scale were assessed every $2.5 \mathrm{~min}$ within $20 \mathrm{~min}$ after the spinal injection and then every $10 \mathrm{~min}$ afterwards. The Ramsay sedation score (RSS) was used to assess sedation ( $1=$ anxious and agitated; 2 = cooperative and tranquil; 3 = drowsy but responsive to verbal commands; 4 = asleep but briskly responsive to tactile stimulation; $5=$ asleep and sluggish responses to stimuli; and 6 = asleep and no response) [12]. The MAP, HR, and $\mathrm{SpO}_{2}$ levels and the RSS were recorded every $5 \mathrm{~min}$.

Hypotension was defined as below $80 \%$ of the baseline mean arterial pressure or below $90 \mathrm{mmHg}$ of systolic blood pressure. If hypotension developed, ephedrine $4 \mathrm{mg}$ was injected intravenously. If the blood pressure drop continued, the same dose was 
injected repeatedly. Bradycardia was defined as $\mathrm{HR}<45$ beats/ $\mathrm{min}$ and was treated with $0.5 \mathrm{mg}$ of intravenous atropine. Desaturation was defined as a $\mathrm{SpO}_{2}$ level of less than $90 \%$ and was treated appropriately.

The primary outcome of this study was a comparison of the durations of spinal sensory and motor blocks among the three groups. The duration of the sensory block was defined as a twodermatome regression from the maximal level. Motor block duration was the time required to return to a modified Bromage scale of 1 after the achievement of 3 . If the maximal modified Bromage scale didn't approach number 3 , motor block duration was defined score 1 after the achievement of 2 . The secondary outcomes were an evaluation of the sedation score and the regression time for RSS which is the time required to return to a RSS of less than 3 after the achievement of a score of 3 . If the maximal RSS didn't approach number 3, regression time of RSS was defined the time to return to a score 2 or under. We also evaluated the side effects of dexmedetomidine, including bradycardia, hypotension, oxygen desaturation and excessive sedation.

The statistical analysis was performed with SAS (Version 9.2, SAS Inc., Cary, NC, USA). Data were expressed as the mean \pm $\mathrm{SD}$, the median (range), or the number of patients. The sample sizes were calculated based on a previous study [5], assuming that the difference in the sensory block duration for pain between the control group and either the D- 0.5 or D-1 group was more than $30 \mathrm{~min}$ on average, $30 \mathrm{~min}$ to the standard deviation, with an alpha error of 0.05 and a power of $80 \%$. A total of 16 patients per group were necessary to be able to demonstrate statistical significance. Therefore, we assigned 20 patients to each group to allow for possible protocol violations during the study period.

To compare the variables between the three groups, the Kolmogorov-Smirnov test was used to identify the variables with a normal distribution. Variables with a normal distribution were compared using an ANOVA test, and those without a normal distribution were compared using the Kruskal-Wallis test. Incidence variables were compared using a chi-square test or Fisher's exact test. All significant results were further analyzed with the Bonferroni post-hoc test. A P value of less than 0.05 was considered to be statistically significant.

\section{Results}

Sixty patients were enrolled in this study, and none were excluded or failed to complete (Fig. 1). In total, data from 60 patients were analyzed, with no differences observed in any of the demographic variables (Table 1).

The time for the two-segment regression of the pinprick sensory block was significantly prolonged in the D-0.5 group (86.5 $\pm 24.3, \mathrm{P}=0.001)$ and the $\mathrm{D}-1$ group $(92.5 \pm 30.7, \mathrm{P}<0.0001)$ compared to the control group $(57.6 \pm 23.2)$. The time for regression of the motor block (Bromage scale from 3 to 1 ) was also significantly prolonged in the D-0.5 group $(132.9 \pm 43.4, \mathrm{P}$ $=0.0152)$ and the $\mathrm{D}-1$ group $(130.4 \pm 50.4, \mathrm{P}=0.024)$ compared

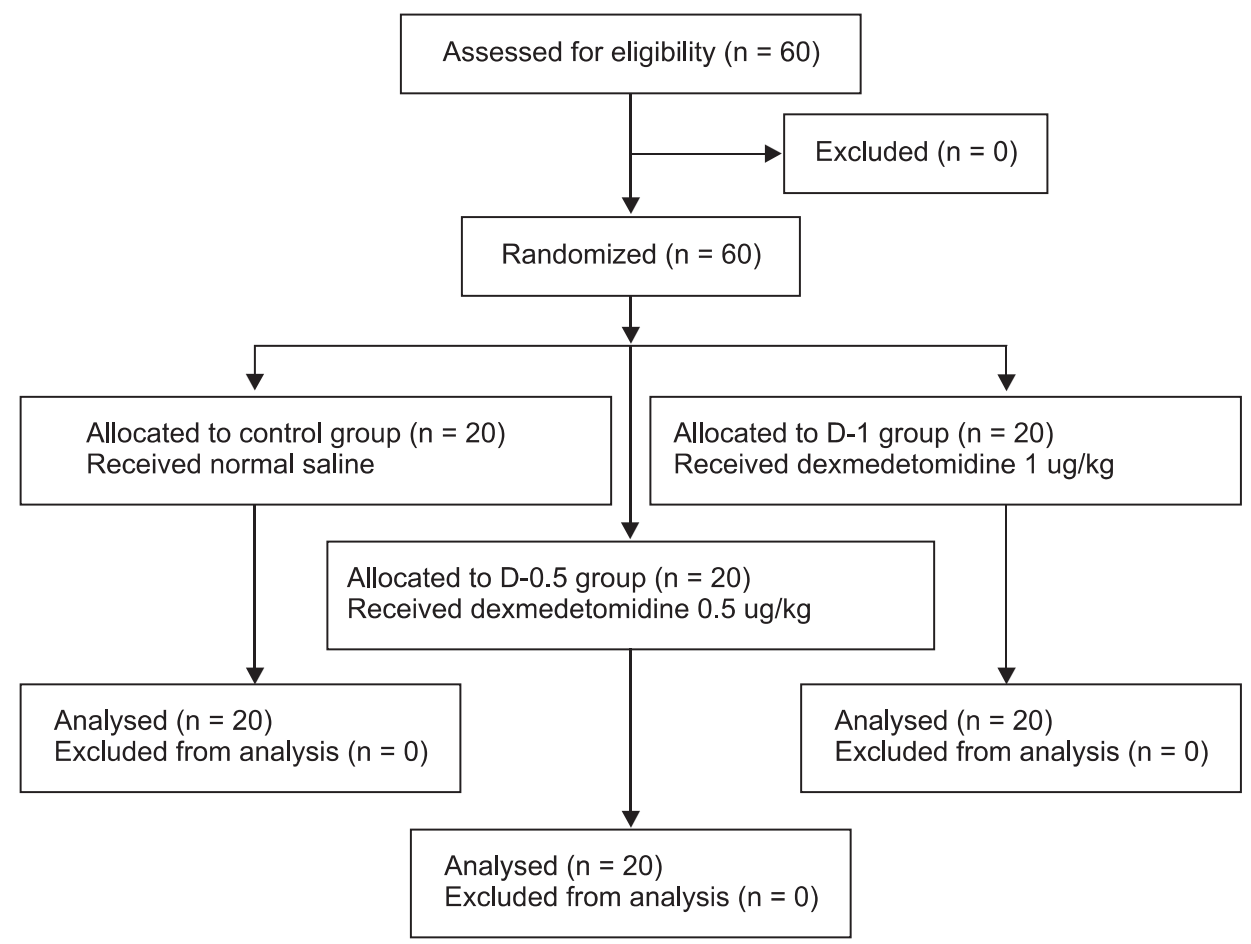

Fig. 1. Flow diagram of the randomized, controlled trial. 
Table 1. Demographic Data and Duration of Surgery

\begin{tabular}{lccc}
\hline & $\begin{array}{c}\text { Control } \\
(\mathrm{n}=20)\end{array}$ & $\begin{array}{c}\mathrm{D}-0.5 \\
(\mathrm{n}=20)\end{array}$ & $\begin{array}{c}\mathrm{D}-1 \\
(\mathrm{n}=20)\end{array}$ \\
\hline Sex $(\mathrm{M} / \mathrm{F})$ & $14 / 6$ & $15 / 5$ & $12 / 8$ \\
Age $(\mathrm{yr})$ & $42.4 \pm 10.5$ & $40.4 \pm 14.9$ & $39.0 \pm 14.9$ \\
Weight $(\mathrm{kg})$ & $65.8 \pm 11.8$ & $65.5 \pm 9.3$ & $68.8 \pm 11.0$ \\
Height $(\mathrm{cm})$ & $167.4 \pm 8.5$ & $168.5 \pm 11.0$ & $167.1 \pm 7.2$ \\
Body Mass Index $\left(\mathrm{kg} / \mathrm{m}^{2}\right)$ & $23.5 \pm 3.1$ & $23.0 \pm 2.3$ & $22.8 \pm 6.1$ \\
Duration of surgery $(\mathrm{min})$ & $58.4 \pm 38.4$ & $60.8 \pm 27.8$ & $56.5 \pm 27.8$ \\
\hline
\end{tabular}

Values are presented as mean \pm SD and the number of patients. No statistically significant differences were observed among the three groups. Control: group with receiving normal saline, D-0.5: group with receiving $0.5 \mathrm{ug} / \mathrm{kg}$ of dexmedetomidine, D-1: group with receiving $1 \mathrm{ug} / \mathrm{kg}$ of dexmedetomidineover 10 min prior to spinal anesthesia.

Table 2. Duration of Spinal Anesthesia, Onset Time, and Maximal Pain Sensory Block Level

\begin{tabular}{lccc}
\hline & $\begin{array}{c}\text { Control } \\
(\mathrm{n}=20)\end{array}$ & $\begin{array}{c}\mathrm{D}-0.5 \\
(\mathrm{n}=20)\end{array}$ & $\begin{array}{c}\mathrm{D}-1 \\
(\mathrm{n}=20)\end{array}$ \\
\hline Time for regression of motor block (Bromage scale 3 to 1) (min) & $98.8 \pm 34.1$ & $132.9 \pm 43.4^{*}$ & $130.4 \pm 50.4^{*}$ \\
Time for two-segment regression of pinprick sensory block (min) & $57.6 \pm 23.2$ & $86.5 \pm 24.3^{*}$ & $92.5 \pm 30.7^{*}$ \\
Time for regression of Ramsay sedation score (<3) (min) & 0 & $83.6 \pm 40.4^{*}$ & $89.9 \pm 42.7^{*}$ \\
Maximal pinprick sensory block level & T8 (L1-T5) & T9 (L1-T6) & T10 (L2-T6) \\
Time to reach the T10 dermatome (min) & $2.5 \pm 3.5$ & $1.8 \pm 2.6$ & $3.1 \pm 3.5$ \\
\hline
\end{tabular}

Values are presented as mean \pm SD and median (range). Control: group with receiving normal saline, D- 0.5 : group with receiving $0.5 \mathrm{ug} / \mathrm{kg}$ of dexmedetomidine, D-1: group with receiving $1 \mathrm{ug} / \mathrm{kg}$ of dexmedetomidineover $10 \mathrm{~min}$ prior to spinal anesthesia. $* \mathrm{P}<0.05$ when compared to control group. No statistically significant differences were observed between group D-0.5 and D-1.

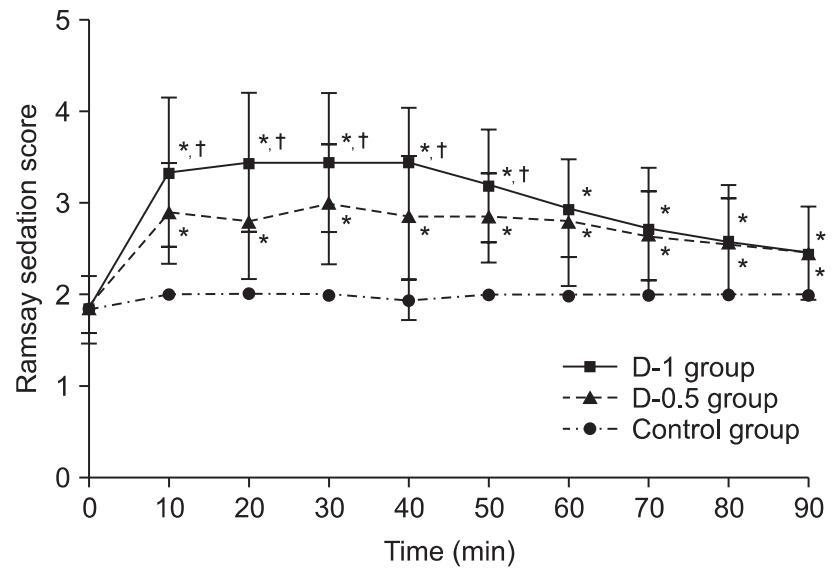

Fig. 2. Ramsay sedation score. Values are presented as mean \pm SD. $* \mathrm{P}<0.05$ when compared to control group. ${ }^{\dagger} \mathrm{P}<0.05 \mathrm{D}$ - 1 group when compared to the value in the $\mathrm{D}-0.5$ group at the same time point.

to the control group $(98.8 \pm 34.1)$. However, there were no statistically significant differences between the D- 0.5 and $\mathrm{D}-1$ groups in the time for two-segment regression of the pinprick sensory block and the time for regression of the motor block (Table 2). The number of patients that maximal modified Bromage scale didn't approach number 3 were 2, 1 , and 2 of 20 patients in the control, D-0.5 and D- 1 groups, respectively.

Fig. 2 shows the RSS at each time point. The RSS were significantly increased in the dexmedetomidine groups than in the control group after following injection of dexmedetomidine. In addition, in the D-1 groups the RSS were significantly higher than in the D- 0.5 group. The excessive sedation (RSS $>4$ ) was observed in 1 of 20 patients and 5 of 20 patients in the D- 0.5 and D-1 groups, respectively. However, there were no patients with oxygen desaturation among the three groups (Table 3 ). The regression time of the RSS $(<3)$ was $83.6 \pm 40.4$ and $89.9 \pm 42.7$ in the D- 0.5 and D- 1 groups, respectively.

The median of the maximal pinprick sensory block level and the time to reach the T10 dermatome level were not statistically different among the groups (Table 2). The heart rate during the study was not statistically different among the groups. The incidences of hypotension and bradycardia requiring treatment also showed no differences among the groups.

\section{Discussion}

Our results indicate that both 0.5 and $1.0 \mathrm{ug} / \mathrm{kg}$ of dexmedetomidine administered as isolated boluses in the absence of maintenance infusions prolonged the duration of sensory and motor block of spinal anesthesia. In dexmedetomidine groups, the sedation score were significantly increased than in the control group, and duration of sedation (regression time of the RSS) was $83.6 \pm 40.4$ and $89.9 \pm 42.7$ in the D-0.5 and D-1 groups, respectively. In addition, no patients showed an oxygen desaturation among the three groups. 
Table 3. Adverse Events

\begin{tabular}{lccc}
\hline & $\begin{array}{c}\text { Control } \\
(\mathrm{n}=20)\end{array}$ & $\begin{array}{c}\mathrm{D}-0.5 \\
(\mathrm{n}=20)\end{array}$ & $\begin{array}{c}\mathrm{D}-1 \\
(\mathrm{n}=20)\end{array}$ \\
\hline Hypotension $(\mathrm{n})$ & 3 & 3 & 0 \\
Treatment needed bradycardia (n) & 1 & 3 & 3 \\
Excessive sedation (Ramsay sedation score 5/6) (n) & $0 / 0$ & $1 / 0$ & $5 * / 0$ \\
Oxygen desaturation $\left(\mathrm{SpO}_{2}<90 \%\right)(\mathrm{n})$ & 0 & 0 & 0 \\
\hline
\end{tabular}

Values are presented as the number of patients. Treatment needed bradycardia, heart rate $<45$ beats/min. Control: group with receiving normal saline, D-0.5: group with receiving $0.5 \mathrm{ug} / \mathrm{kg}$ of dexmedetomidine, D-1: group with receiving $1 \mathrm{ug} / \mathrm{kg}$ of dexmedetomidineover 10 min prior to spinal anesthesia. $* \mathrm{P}<0.05$ when compared to control group.

Several clinical studies have investigated the effects of intravenous dexmedetomidine on spinal anesthesia. Previous studies used various doses and types of local anesthetics for spinal anesthesia as well as various doses and infusion methods of intravenous dexmedetomidine, so it is not easy to reliable translation into clinical practice. Mostly, dexmedetomidine was administered at an initial loading dose from 0.25 to $1 \mathrm{ug} / \mathrm{kg}$, and/or a maintenance infusion with rates between 0.2 and $0.5 \mathrm{ug} / \mathrm{kg} / \mathrm{h}$ throughout the duration of surgery [5-10]. According to the results of previous clinical studies, intravenous dexmedetomidine can prolong the duration of sensory blockade and, to a lesser extent, prolong the motor blockade duration [13]. However, few studies have directly compared different amounts of dexmedetomidine. In particular, $0.5 \mathrm{ug} / \mathrm{kg}$ and $1 \mathrm{ug} / \mathrm{kg}$ are commonly used doses in clinical practice. In our study, single doses of $0.5 \mathrm{ug} / \mathrm{kg}$ and $1 \mathrm{ug} / \mathrm{kg}$ of dexmedetomidine prolonged the two-segment regression times of the sensory block and motor block. However, there were no statistically significant differences in the duration of spinal anesthesia between the D-1 and the D- 0.5 group. It should be noted that an analgesic ceiling effect of dexmedetomidine was apparent at a dose of $0.5 \mathrm{ug} / \mathrm{kg}$ in a previous study [14].

The mechanism of intravenous dexmedetomidine on spinal anesthesia remains unclear; however, supra-spinal, direct analgesia, and/or vasoconstriction activities are involved [15]. Moreover, dexmedetomidine produces a greater degree of differential blockade by preferentially blocking the myelinated A a-fibers involved in sensory conduction over the unmyelinated $\mathrm{C}$ fibers involved in motor conduction [13].

The administration of intravenous dexmedetomidine in spinal anesthesia may actually have a dual effect by both enhancing the local anesthetic action and providing sedation. Dexmedetomidine affects the locus caeruleus area of the brain, which induces sedation resembling natural sleep by means of sleep modulation and respiration control $[3,16]$. It is correlated with cooperative sedation, which is different from the clouding of consciousness that occurs with drugs that act on GABA receptors, such as propofol or midazolam [17]. In a previous study, dexmedetomidine showed better oxygen saturation and RSS than midazolam [18]. In the present study, dexmedetomidine provided sufficient sedation ( 0 vs $83.6 \pm 40.4$ vs $89.9 \pm 42.7 \mathrm{~min}$ ), and the duration did not differ between the D-0.5 and D-1 groups. Although the excessive sedation (RSS $>4$ ) was observed in 1 of 20 patients and 5 of 20 patients in the D- 0.5 and D- 1 groups, respectively, there were no patients with oxygen desaturation.

In spite of its many advantages as a sedative drug, dexmedetomidine causes increase in the incidence of bradycardia [19]. It is related to decreases in plasma catecholamine concentrations and the sympathetic outflow caused by $\alpha_{2}$-adrenergic activation. The incidence of bradycardia was higher in studies where the dexmedetomidine initial loading dose was infused over a short duration (5 $\mathrm{min}$ ) [6]. However, bradycardia was transient and reversed with intravenous atropine. In our study, the loading dose was infused over a $10 \mathrm{~min}$, and there were no statistically significant differences ( 1 vs 3 vs 3 ) among the three groups.

In this study, we investigated the effects of dexmedetomidine on spinal anesthesia with only two doses, 0.5 and $1.0 \mathrm{ug} / \mathrm{kg}$. Therefore, it is difficult to discuss the dose-response relationship of the dexmedetomidine dose and the spinal anesthesia duration. Further studies are needed to determine the dose-response relationship.

In conclusion, both 0.5 and $1.0 \mathrm{ug} / \mathrm{kg}$ of dexmedetomidine administered as isolated boluses in the absence of maintenance infusions prolonged the duration of spinal anesthesia. In addition dexmedetomidine group showed the higher sedation score than in the control group without oxygen desaturation.

\section{References}

1. Kamibayashi T, Maze M. Clinical uses of alpha 2-adrenergic agonists. Anesthesiology 2000; 93: 1345-9.

2. Fragen RJ, Fitzgerald PC. Effect of dexmedetomidine on the minimum alveolar concentration (MAC) of sevoflurane in adult age 55-70 years. J Clin Anesth 1999; 11: 466-70. 
3. Guo TZ, Jiang JY, Buttermann AE, Maze M. Dexmedetomidine injection into the locus ceruleus produces antinociception. Anesthesiology 1996; 84: 873-81.

4. Jorm CM, Stamford JA. Actions of the hypnotic anaesthetic, dexmedetomidine, on noradrenaline release and cell firing in rat locus ceruleus slices. Br J Anaesth 1993; 71: 447-9.

5. Jung SH, Lee SK, Lim KJ, Park EY, Kang MH, Lee JM, et al. The effects of single-dose intravenous dexmedetomidine on hyperbaric bupivacaine spinal anesthesia. J Anesth 2013; 27: 380-4.

6. Hong JY, Kim WO, Yoon Y, Choi Y, Kim SH, Kil HK. Effects of intravenous dexmedetomidine on low-dose bupivacaine spinal anesthesia in elderly patients. Acta Anaesthesiol Scand 2012; 56: 382-7.

7. Kaya FN, Yavascaoglu B, Turker G, Yildirim A, Gurbet A, Mogol EB, et al. Intravenous dexmedetomidine, but not midazolam, prolongs bupivacaine spinal anesthesia. Can J Anesth 2010; 57: 39-45.

8. Al-Mustafa MM, Badran IZ, Abu-Ali HM, Al-Barazangi BA, Massad IM, Al-Ghanem SM. Intravenous dexmedetomidine prolongs bupivacaine spinal analgesia. Middle East J Anesthesiol 2009; 20: 225-31.

9. Elcicek K, Tekin M, Kati I. The effects of intravenous dexmedetomidine on spinal hyperbaric ropivacaine anesthesia. J Anesth 2010; 24: 5448.

10. Tekin M, Kati I, Tomak Y, Kisli E. Effect of dexmedetomidine IV on the duration of spinal anesthesia with prilocaine: A double-blind, prospective study in adult surgical patients. Curr Ther Res Clin Exp 2007; 68: 313-24.

11. Bromage PR. A comparison of the hydrochloride and carbon dioxide salts of lidocaine and prilocaine in epidural analgesia. Acta Anaesthesiol Scand Suppl 1965; 16: 55-69.

12. Ramsay MA, Savege TM, Simpson BR, Goodwin R. Controlled sedation with alphaxalone-alphadolone. Br Med J 1974; $2: 656-9$.

13. Abdallah FW, Abrishami A, Brull R. The facilitatory effects of intravenous dexmedetomidine on the duration of spinal anesthesia: a systemic review and meta-analysis. Anesth Analg 2013; 117: 271-8.

14. Jaakola ML, Salonen M, Lehtinen R, Scheinin H. The analgesia action of dexmedetomidine -a novel alpha 2-adrenoceptor agonist-in healthy volunteer. Pain 1991; 46: 281-5.

15. Saadawy I, Boker A, Elshahawy MA, Almazrooa A, Melibary S, Abdellatif AA, et al. Effect of dexmedetomidine on the characteristics of bupivacaine in a caudal block in pediatrics. Acta Anaesthesiol Scand 2009; 53: 251-6.

16. Huupponen E, Maksimow A, Lapinlampi P, Särkelä M, Saastamoinen A, Snapir A, et al. Electroenecephalogram spindle activity during dexmedetomidine sedation and physiological sleep. Acta Anaesthesiol Scand 2008; 52: 289-94.

17. Aho M, Erkola O, Kallio A, Scheinin H, Korttila K. Comparison of dexmedetomidine and midazolam sedation and antagonism of dexmedetomidine with atpamezole. J Clin Anesth 1993; 5: 194-203.

18. Wu W, Chen Q, Zhang LC, Chen WH. Dexmedetomidine versus midazolam for sedation in upper gastrointestinal endoscopy. J Int Med Res 2014; 42: 516-22.

19. Niu XY, Ding XB, Guo T, Chen MH, Fu SK, Li Q. Effects of intravenous and intrathecal dexmedetomidine in spinal anesthesia: a metaanalysis. CNS Neurosci Ther 2013; 19: 897-904. 